\title{
ANALISIS POTENSI INDUSTRI UMKM BATIK DI SURABAYA MENGGUNAKAN SISTEM INFORMASI GEOGRAFIS
}

\author{
Muhammad Taufik ${ }^{1}$, Wijaya Justian ${ }^{2}$ \\ ${ }^{1,2}$ Departemen Teknik Geomatika, Fakultas Teknik Sipil Lingkungan dan Kebumian, Institut Teknologi Sepuluh \\ Nopember (ITS), Jl. Arief Rahman Hakim, Surabaya 60111 Indonesia

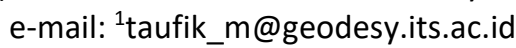

\begin{abstract}
Abstrak
Dibalik perlambatan pertumbuhan ekonomi global sektor UMKM memegang peranan yang sangat penting dalam menjaga kestabilan ekonomi nasional. Pada tahun 2016 kontribusi sektor UMKM mencapai 60,34\% bagi produk domestik bruto (PDB) nasional. Batik sendiri merupakan warisan budaya nusantara yang sudah diakui oleh dunia melalui UNESCO yaitu sebagai karya agung warisan kemanusiaan untuk budaya lisan dan nonbendawi (Masterpiece of The Oral and Intangible Heritage of Humanity). Sehingga dalam rangka mendukung dan mengembangkan sektor UMKM batik di Surabaya dibutuhkan suatu sistem untuk memonitoring dan menganalisis potensi UMKM batik di Surabaya yaitu dengan dibangunnya sistem informasi geografis.

Tujuan penelitian ini adalah membuat peta potensi UMKM batik kota Surabaya dan SIG potensi UMKM batik kota Surabaya, yang diperoleh menggunakan metode skoring berdasarkan parameter jarak terhadap akses transportasi, rentang harga, dan kelengkapan produk UMKM batik di Surabaya. Sebagai referensi dan rekomendasi bagi pihak-pihak terkait dalam mengembangkan potensi UMKM batik di Surabaya.

Hasil analisa potensi UMKM batik di Surabaya diklasifikasikan menjadi 3 klasifikasi prioritas yaitu prioritas tinggi, sedang, dan rendah. Hasil analisa wilayah yang mempunyai UMKM batik dengan prioritas tinggi yaitu banyak terdapat di Surabaya Selatan yaitu pasar DTC, prioritas sedang banyak terdapat di Surabaya Pusat yaitu pasar Turi, pasar PGS dan Surabaya Utara yaitu pasar Atum, sedangkan prioritas rendah banyak terdapat di Surabaya Timur yaitu Pasar ITC.
\end{abstract}

Kata Kunci : Potensi UMKM Batik, Sistem Informasi Geografis, Analisa Skoring.

\begin{abstract}
Behind the slowing global economic growth, MSME sector plays a very important role in maintaining the stability of national economy. In 2016 the contribution of the MSME sector reaches 60.34\% for the national gross domestic product (GDP). Batik itself is a cultural heritage of the archipelago that has been recognized by the world through UNESCO as a masterpiece of humanitarian heritage for oral and nonbendawi culture (Masterpiece of The Oral and Intangible Heritage of Humanity). So in order to support and develop the sector of batik MSMEs in Surabaya required a system to monitor and analyze the potential of MSMEs in Surabaya batik is the construction of geographic information systems.

The purpose of this research is to make a potential map of MSMEs of Surabaya city batik and GIS potency of batik MSME Surabaya city, which obtained by using scoring method based on distance parameter to transportation access, price range and completeness of batik product MSMEs in Surabaya. As reference and recommendation for related parties in developing potency of batik MSMEs in Surabaya.

The results of the potential analysis of batik MSMEs in Surabaya are classified into 3 priority classification of high, medium, and low priority. Results of regional analysis that has MSMEs batik with high priority that is 13 MSMEs spread in South Surabaya amounted to 5 MSMEs, Central Surabaya amounted to 6 MSMEs, and North Surabaya amounted to 2 MSMEs. Then the medium priority of 24 MSMEs spread in South Surabaya amounted to 5 MSMEs, Central Surabaya amounted to 17 MSMEs, and North Surabaya amounted to 2 MSMEs. While the low priority of 4 MSMEs spread across Central Surabaya amounted to 1 MSMEs and North Surabaya amounted to 3 MSMEs.
\end{abstract}

Keywords : Potential of MSMEs Batik, Geographic Information System, Scoring Analysis. 


\section{PENDAHULUAN}

Pertumbuhan ekonomi global belakangan ini berada dalam trend perlambatan. Pada 2016 pertumbuhan ekonomi global hanya mencapai $3,2 \%$. Angka tersebut jauh jika dibandingkan pertumbuhan ekonomi global tahun 2011 yang mencapai 5,4\% (International Monetary Fund, 2017). Melambatnya ekonomi global menjadi salah satu dampak pada lesunya ekonomi di Indonesia. Daya beli masyarakat mengalami penurunan hampir di semua sektor usaha.

UMKM merupakan singkatan dari usaha mikro, kecil dan menengah. UMKM diatur berdasarkan UU Nomor 20 tahun 2008 tentang usaha mikro, kecil,dan menengah. Dimana UMKM adalah usaha ekonomi produktif yang berdiri sendiri, yang dilakukan oleh orang perseorangan atau badan usaha yang bukan merupakan anak perusahaan atau cabang perusahaan yang dimiliki, dikuasai, atau menjadi bagian baik langsung maupun tidak langsung dengan Usaha Kecil atau usaha besar dengan jumlah kekayaan bersih atau hasil penjualan tahunan sebagaimana diatur dalam Undang-Undang (UU RI No 20, 2008). Dibalik perlambatan ekonomi saat ini, sektor UMKM menjadi salah satu kontributor yang sangat baik bagi kestabilan ekonomi nasional. Kemampuan UMKM sudah terbukti mampu menopang perekonomian saat krisis ekonomi 1997-1998. Pada tahun 2016 kontribusi sektor UMKM mencapai $60,34 \%$ bagi produk domestik bruto (PDB) nasional (Badan Pusat Statistik, 2017).

Surabaya merupakan salah satu kota metropolitan sekaligus ibukota provinsi Jawa Timur. Oleh karena itu Surabaya menjadi pusat kegiatan perekonomian di Jawa Timur dan sekitarnya, sehingga Surabaya memiliki peran yang besar dalam menciptakan lapangan pekerjaan untuk warga Surabaya dan daerah lain sekitar Surabaya.

Batik merupakan warisan budaya nusantara (Indonesia) yang mempunyai nilai dan perpaduan seni yang tinggi, sarat dengan makna filosofis dan simbol penuh makna yang memperlihatkan cara berpikir masyarakat pembuatnya. Batik adalah kerajinan yang telah menjadi bagian dari budaya Indonesia (khususnya Jawa) sejak dahulu (Musman \& Arini, 2011). Keterampilan membatik digunakan sebagai mata pencaharian dan pekerjaan ekslusif bagi perempuan-perempuan Jawa hingga sampai ditemukannya batik cap dan printing yang memungkinkan masuknya laki-laki dalam pekerjaan membatik ini. Perkembangan batik di Indonesia memuncak pada tanggal 2 Oktober 2009, yakni UNESCO (United Nation Educational, Scientific and Cultural Organization) menetapkan Batik Indonesia sebagai sebuah keseluruhan teknik, teknologi, pengembangan motif dan budaya yang terkait dengan batik tersebut sebagai karya agung warisan kemanusiaan untuk budaya lisan dan nonbendawi (Masterpiece of The Oral and Intangible Heritage of Humanity) yaitu pengakuan internasional bahwa batik Indonesia adalah bagian kekayaan peradaban manusia.

Sistem Informasi Geografis dapat dimanfaatkan untuk mendukung kegiatan UMKM di bidang batik yang ada di kota Surabaya. Analisis spasial UMKM yang dihasilkan dari SIG dapat memudahkan bagi pihak terkait dalam membuat suatu keputusan. Informasi yang dihasilkan SIG dapat dibuat dengan detail sehingga kebutuhan akan informasi akan sangat terpenuhi.

\section{METODE}

\section{Lokasi Penelitian}

Lokasi penelitian adalah di Kota Surabaya, Provinsi Jawa Timur. Kota Surabaya memiliki luas sekitar $350,5 \mathrm{~km} 2$ dan secara geografis terletak di antara $7^{\circ} 09^{\prime} \mathrm{s} / \mathrm{d} 7^{\circ} 21^{\prime}$ Lintang Selatan dan $112^{\circ} 36^{\prime} \mathrm{s} / \mathrm{d}$ $112^{\circ} 54^{\prime}$.

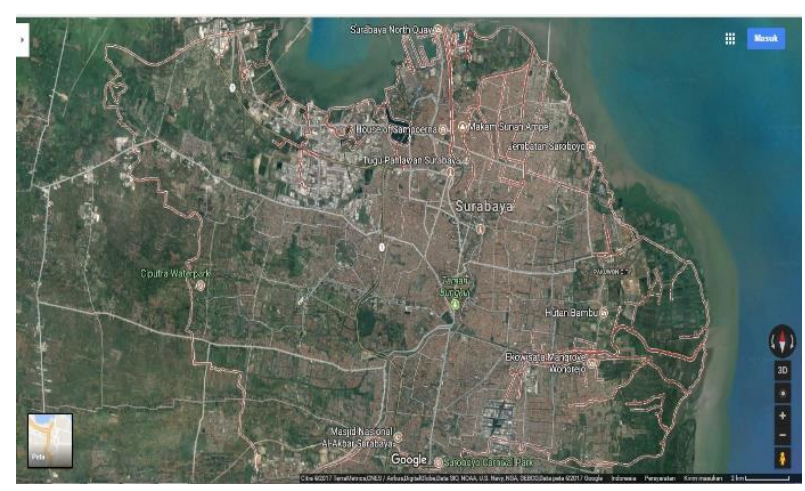

Gambar 1. Lokasi Penelitian

(Sumber : Google Maps 2017)

\section{Data dan Peralatan}

a. Data 
Data yang digunakan dalam penelitian ini yaitu meliputi berikut:

1. Data spasial berupa peta digital kota Surabaya dalam format (.shp) dan hasil koordinat dari GPS.

2. Data non spasial yang digunakan adalah data primer (survei kuisioner) dan data sekunder mengenai UMKM batik di kota Surabaya dari Dinas Koperasi Usaha Mikro Kecil dan Menengah Kota Surabaya.

b. Peralatan

Peralatan atau perangkat lunak (sofware) yang digunakan dalam penelitian ini yaitu

1. Windows 10

2. Microsoft Office 2016

3. ArcGIS 10.0

4. CarryMap

\section{Tahap Pengolahan Data}

Adapun tahap pengolahan dapat dejelaskan sebagai berikut.

1. Data sekunder yang dibutuhkan yaitu data spasial berupa peta digital kota Surabaya skala 1:5000 dan data non spasial berupa data usaha UMKM batik di Surabaya.

2. Survey Lokasi UMKM Batik

Pada tahap ini dilakukan proses survei ke lapangan untuk memperoleh data primer yang berupa koordinat UMKM batik dan verifikasi lokasi UMKM batik yang sudah ada.

3. Survey Kuisioner pada Pemilik UMKM

Tahap ini dilakukan bersamaan saat survey lokasi UMKM batik dengan menggunakan kuisioner yang ditujukan kepada pemilik UMKM, pertanyaan kuisioner berkaitan dengan atribut yang akan digunakan saat penyusunan SIG UMKM batik.

4. Penyusunan SIG UMKM Batik di Surabaya Penyusunan SIG UMKM batik merupakan penggabungan dan penyusunan data spasial berupa koordinat-koordinat dan data non spasial berupa atribut-atribut yang diperoleh menjadi SIG UMKM batik yang akan digunakan untuk menganalisa potensi UMKM batik.

5. Pemberian Bobot
Pemberian bobot merupakan kegiatan yang bertujuan untuk menentukan bobot masing-masing dengan parameter potensi yang mempengaruhi bagi UMKM batik.

6. Analisa Skoring Menggunakan Metode SAW yang dilakukan untuk mendapatkan informasi mengenai UMKM batik yang berpotensi menjadi tempat rekomendasi UMKM batik di Surabaya.

7. Analisa Potensi UMKM Batik berdasarkan kriteria parameter - parameter UMKM batik di Surabaya.

8. Peta Potensi UMKM Batik di Surabaya dapat diperoleh setelah mendapatkan hasil dari analisa potensi UMKM batik di Surabaya.

9. Aplikasi Potensi UMKM Batik di Surabaya menggunakan CarryMap untuk memudahkan para pengguna dalam menggunakan SIG batik di Surabaya.

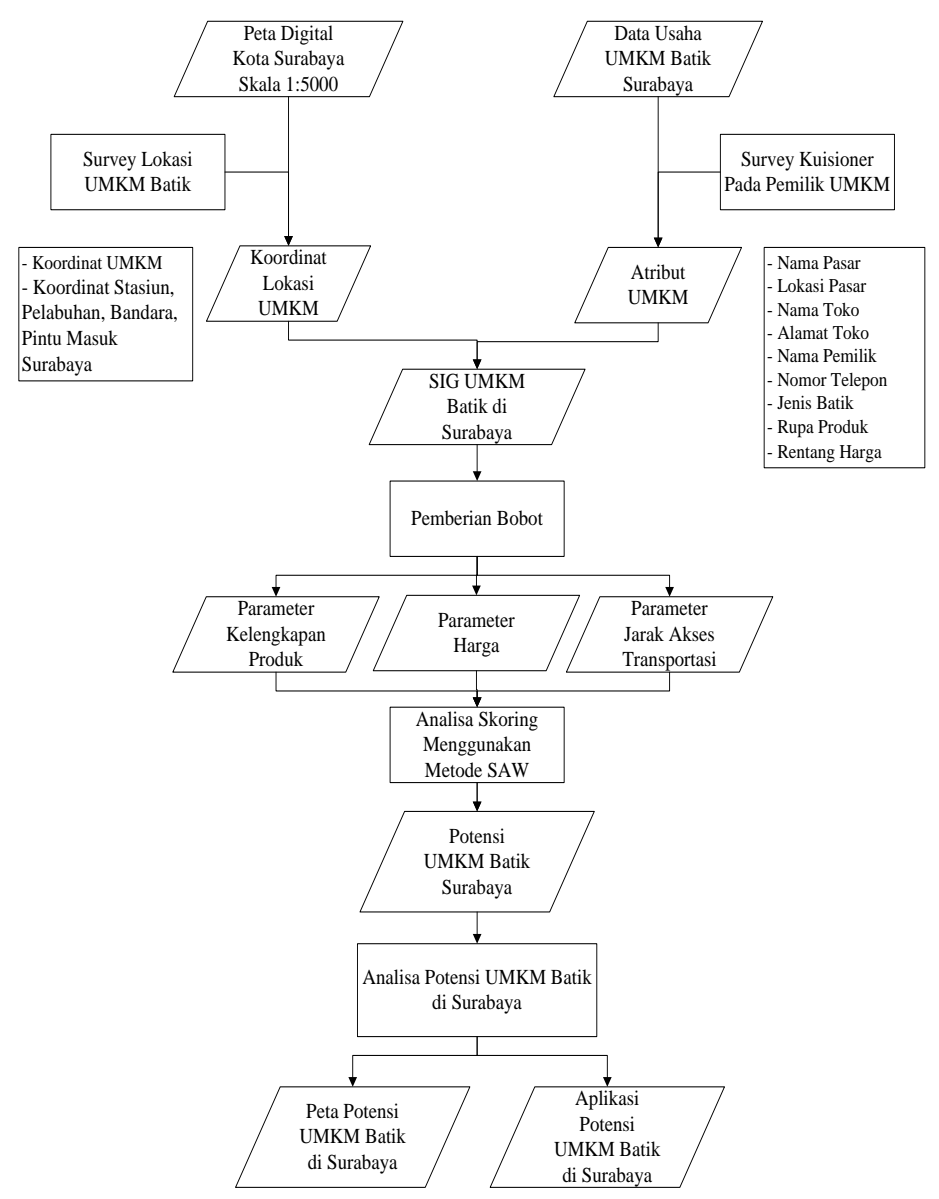

Gambar 2. Diagram Alir Pengolahan Data 


\section{HASIL DAN PEMBAHASAN}

\section{Perhitungan Bobot}

Sebelum melakukan analisa skoring pada masing masing kriteria, maka diperlukan menghitung bobotnya terlebih dahulu yaitu dengan metode pairwise comparison. Sehingga diperoleh bobot ternormalisasi masing - masing parameternya sebagai berikut:

Tabel 1. Nilai Bobot Parameter

\begin{tabular}{lc}
\hline \multicolumn{1}{c}{ Parameter } & Bobot \\
\hline Jarak Akses Transportasi (JAT) & 0,334 \\
Harga (H) & 0,334 \\
Jenis Produk (JP) & 0,334 \\
\hline \multicolumn{1}{c}{ Jumlah } & 1 \\
\hline
\end{tabular}

Pemberian bobot dilakukan untuk menentukan tingkat kepentingan antara kriteria yang satu dengan kriteria yang lain.

\section{Kriteria Jarak Akses Transportasi}

Kriteria jarak terhadap akses transportasi bertujuan untuk mengetahui UMKM Batik yang dekat terhadap akses transportasi. Pada penelitian ini akses transportasi yang dimaksud adalah stasiun, terminal, dan pelabuhan yang ada di Surabaya. Dengan asumsi bahwa orang berjalan kaki mempunyai kecepatan rata - rata $5-10$ $\mathrm{km} / \mathrm{jam}$ jika menempuh jarak $2.5 \mathrm{~km}$ maka membutuhkan waktu baginya untuk sampai lokasi UMKM adalah 15 - 30 menit. Sedangkan orang yang menaiki kendaraan di kota mempunyai kecepatan rata - rata $20-40 \mathrm{~km} / \mathrm{jam}$ jika menempuh jarak $2.5 \mathrm{~km}$ maka membutuhkan waktu baginya untuk sampai lokasi UMKM adalah $4-7.5$ menit. Sehingga jarak $2.5 \mathrm{~km}$ dianggap wajar oleh penulis untuk memperoleh skor tertinggi dengan skor 15 dan skor terendah lebih dari $5 \mathrm{~km}$ dengan skor 5 .

\begin{tabular}{ccc}
\multicolumn{3}{c}{ Tabel 2. Parameter Jarak Akses Transportasi } \\
\hline No & $\begin{array}{c}\text { Parameter Jarak Terhadap Akses } \\
\text { Transportasi }\end{array}$ & Skor \\
& $0-2.5 \mathrm{~km}$ & \\
\hline 1 & $2.5-5 \mathrm{~km}$ & 15 \\
2 & $>5 \mathrm{~km}$ & 10 \\
3 & & 5 \\
\hline
\end{tabular}

Maka hasil dari pengolahan data di atas adalah sebagai berikut.

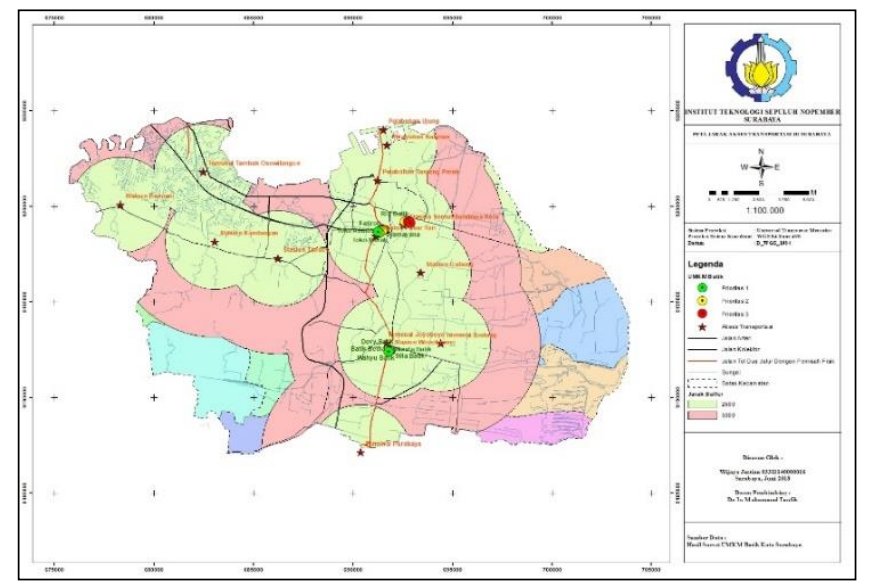

Gambar 3. Peta Skor Jarak UMKM Terhadap Akses Transportasi

Berdasarkan kriteria jarak terhadap akses transportasi, semua UMKM batik mempunyai skor tinggi dengan skor 15, karena UMKM batik mempunyai jarak $<2.5 \mathrm{~km}$ dari transportasi pintu akses masuk Surabaya antara lain stasiun.

Tabel 3. Perhitungan UMKM Batik Berdasarkan Jarak

\begin{tabular}{ccccc}
\hline No & Jarak & Skor & $\begin{array}{c}\text { Jumlah } \\
\text { UMKM }\end{array}$ & $\begin{array}{c}\text { Presentasi } \\
(\%)\end{array}$ \\
\hline 1 & $0-2.5 \mathrm{~km}$ & 15 & 41 & 100 \\
2 & $2.5-5 \mathrm{~km}$ & 10 & 0 & 0 \\
3 & $>5 \mathrm{~km}$ & 5 & 0 & 0 \\
\hline & Jumlah & & 41 & 100 \\
\hline
\end{tabular}

\section{Kriteria Harga Terhadap Daya Beli Masyarakat} Kriteria harga terhadap daya beli masyarakat bertujuan untuk mengetahui UMKM yang mempunyai harga ekonomis yang dapat dijangkau oleh masyarakat dari masyarakat ekonomi menengah ke bawah sampai masyarakat ekonomi menengah ke atas.

Tabel 4. Parameter Harga Terhadap Daya Beli Masyarakat

\begin{tabular}{cccc}
\hline No & Rentang Harga UMKM & Kelas & Skor \\
\hline 1 & Rp. $30.000-100.000$ & ekonomis & 9 \\
2 & Rp. $100.000-200.000$ & $\begin{array}{c}\text { menengah ke } \\
\text { bawah }\end{array}$ & 7 \\
& Rp. $200.000-300.000$ & $\begin{array}{c}\text { menengah } \\
\text { menengah ke }\end{array}$ & 5 \\
3 & Rp. $300.000-500.000$ & $\begin{array}{c}\text { atas } \\
\text { atas }\end{array}$ & 1 \\
\hline
\end{tabular}


Berdasarkan kriteria harga, UMKM batik yang mempunyai presentasi tertinggi yaitu dengan skor 7 sejumlah 26 UMKM, sedangkan yang mempunyai presentasi terendah yaitu dengan skor 3 sejumlah 1 UMKM.

Tabel 5. Perhitungan UMKM Batik Berdasarkan Harga

\begin{tabular}{ccccc}
\hline No & Rentang Harga & Skor & $\begin{array}{c}\text { Jumlah } \\
\text { UMKM }\end{array}$ & $\begin{array}{c}\text { Presentasi } \\
(\%)\end{array}$ \\
\hline 1 & Rp. $30.000-100.000$ & 9 & 4 & 10 \\
2 & Rp. $100.000-200.000$ & 7 & 26 & 64 \\
3 & Rp. $200.000-300.000$ & 5 & 7 & 17 \\
4 & Rp. $300.000-500.000$ & 3 & 1 & 2 \\
5 & Rp. $500.000<$ & 1 & 3 & 7 \\
\hline & Jumlah & & 41 & 100 \\
\hline
\end{tabular}

\section{Kriteria Jenis Produk Terhadap Kelengkapan Produk}

Kriteria kelengkapan produk bertujuan untuk mengetahui UMKM yang mempunyai produk lengkap. Produk lengkap yang dimaksud adalah dimulai dari produk aksesoris, bahan kain, baju anak, dan baju dewasa. Semakin lengkap produknya, maka semakin tinggi nilai skornya.

\begin{tabular}{ccc}
\multicolumn{3}{c}{ Tabel 6. Parameter Jenis Produk } \\
\hline No & Jenis Produk & Skor \\
\hline 1 & Dewasa, Baju Anak, Bahan Kain / \\
Aksesoris & 3 \\
\hline 2 & $\begin{array}{c}\text { Dewasa, Baju Anak } \\
\text { Dewasa, Bahan Kain } \\
\text { Dewasa, Aksesoris }\end{array}$ & 2 \\
\hline 3 & Dewasa & 1 \\
\hline
\end{tabular}

Berdasarkan kriteria produk, UMKM batik yang mempunyai presentasi tertinggi yaitu dengan skor 1 sejumlah 22 UMKM, sedangkan yang mempunyai presentasi terendah yaitu dengan skor 3 sejumlah 2 UMKM.

Tabel 7. Perhitungan UMKM Batik Berdasarkan Produk

\begin{tabular}{|c|c|c|c|c|}
\hline No & Produk & Skor & $\begin{array}{l}\text { Jumlah } \\
\text { UMKM }\end{array}$ & $\begin{array}{c}\text { Presentasi } \\
\text { (\%) }\end{array}$ \\
\hline 1 & $\begin{array}{c}\text { Dewasa, Baju Anak, } \\
\text { Bahan Kain / Aksesoris }\end{array}$ & 3 & 2 & 5 \\
\hline \multirow{3}{*}{2} & Dewasa, Baju Anak & & 9 & 22 \\
\hline & Dewasa, Bahan Kain & 2 & 7 & 17 \\
\hline & Dewasa, Aksesoris & & 1 & 2 \\
\hline \multirow[t]{2}{*}{3} & Dewasa & 1 & 22 & 54 \\
\hline & Jumlah & & 41 & 100 \\
\hline
\end{tabular}

\section{Analisa Potensi UMKM Batik}

Dari ketiga analisa diatas yaitu analisa kriteria jarak, harga, dan kelengkapan produk maka dapat diperoleh UMKM yang mempunyai skor tertinggi dan skor terendah. UMKM batik yang mempunyai total skor tertinggi yaitu dengan skor 8,667 dan mempunyai total skor terendah yaitu dengan skor 5,667. Penulis membagi potensi UMKM batik menjadi 3 prioritas yaitu UMKM dengan prioritas tinggi atau prioritas 1 yaitu dengan skor 8 - 8.9, UMKM prioritas sedang atau prioritas 2 yaitu dengan skor 7 - 7.9, dan UMKM prioritas rendah atau prioritas 3 yaitu dengan skor 5 - 6.9.

Tabel 8. Perhitungan Prioritas UMKM Batik di Surabaya

\begin{tabular}{ccccc} 
No & Prioritas & Skor & Jumlah UMKM & Presentasi (\%) \\
\hline 1 & 1 & $8-8.9$ & 13 & 32 \\
2 & 2 & $7-7.9$ & 24 & 58 \\
3 & 3 & $5-6.9$ & 4 & 10 \\
\hline \multicolumn{3}{c}{ Jumlah } & 41 & 100 \\
\hline
\end{tabular}

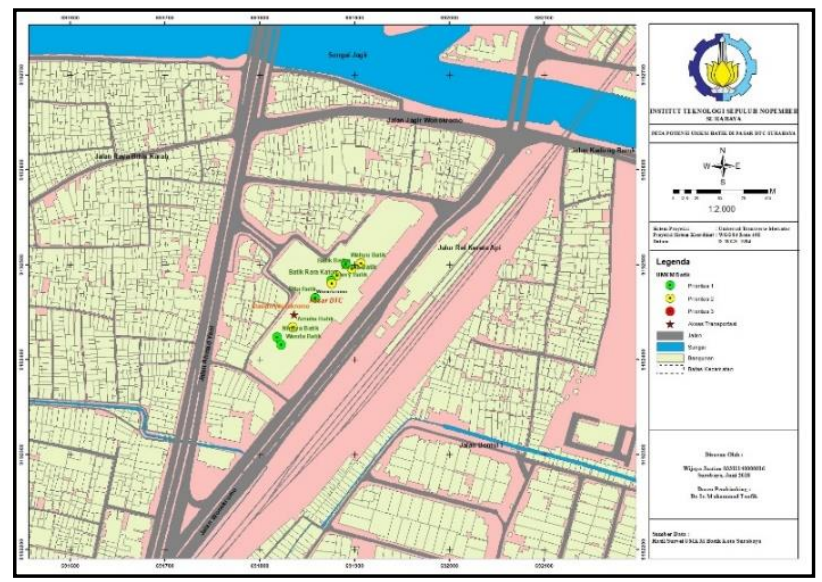

Gambar 4. Peta Prioritas UMKM Batik di Pasar DTC

UMKM yang termasuk prioritas tinggi atau prioritas 1 sebanyak 13 unit. Persebaran UMKM prioritas 1 yaitu antara lain 5 UMKM di Surabaya Selatan yaitu di pasar DTC, 6 UMKM di Surabaya Pusat yaitu 3 di pasar Turi dan 3 di pasar PGS, dan 2 UMKM di Surabaya Utara yaitu 1 di pasar Atom dan 1 di pasar ITC. Hasil pengolahan data dapat dilihat pada tabel 9. 
Tabel 9. Daftar dan Total Skor UMKM Batik Prioritas I

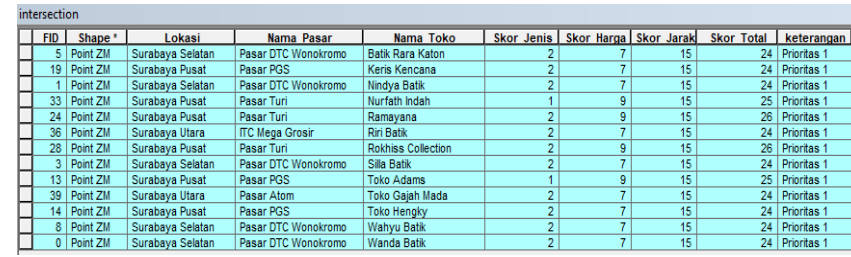

UMKM yang termasuk prioritas sedang atau prioritas 2 sebanyak 24 unit. Persebaran UMKM prioritas 2 yaitu antara lain 5 UMKM di Surabaya Selatan yaitu di pasar DTC, 17 UMKM di Surabaya Pusat yaitu 10 di pasar Turi dan 7 di pasar PGS, dan 2 UMKM di Surabaya Utara yaitu 1 di pasar Atom dan 1 di pasar ITC. Hasil pengolahan data dapat dilihat pada tabel 10.

Tabel 10. Daftar dan Total Skor UMKM Batik Prioritas II

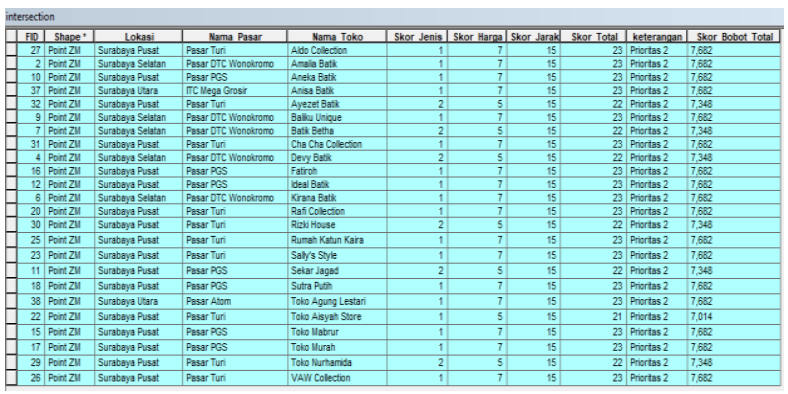

UMKM yang termasuk prioritas rendah atau prioritas 3 sebanyak 4 unit. Persebaran UMKM prioritas 3 yaitu antara lain 1 UMKM di Surabaya Pusat yaitu di pasar Turi, 3 UMKM di Surabaya Utara yaitu di pasar ITC. Hasil pengolahan data dapat dilihat pada tabel 11 .

Tabel 11. Daftar dan Total Skor UMKM Batik Prioritas III

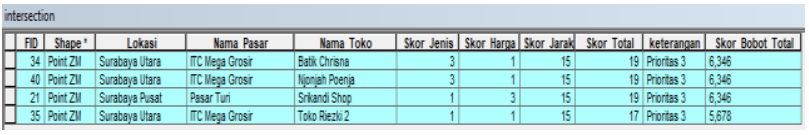

Tampilan Aplikasi SIG Potensi UMKM Batik di Surabaya

SIG Potensi UMKM Batik di Surabaya memiliki tampilan menu identify. Identify pada peta diberikan untuk membantu pengguna dalam memahami informasi-informasi yang terdapat dalam persebaran UMKM batik tersebut. Hasil informasi identifikasi ini akan muncul di sebelah peta.

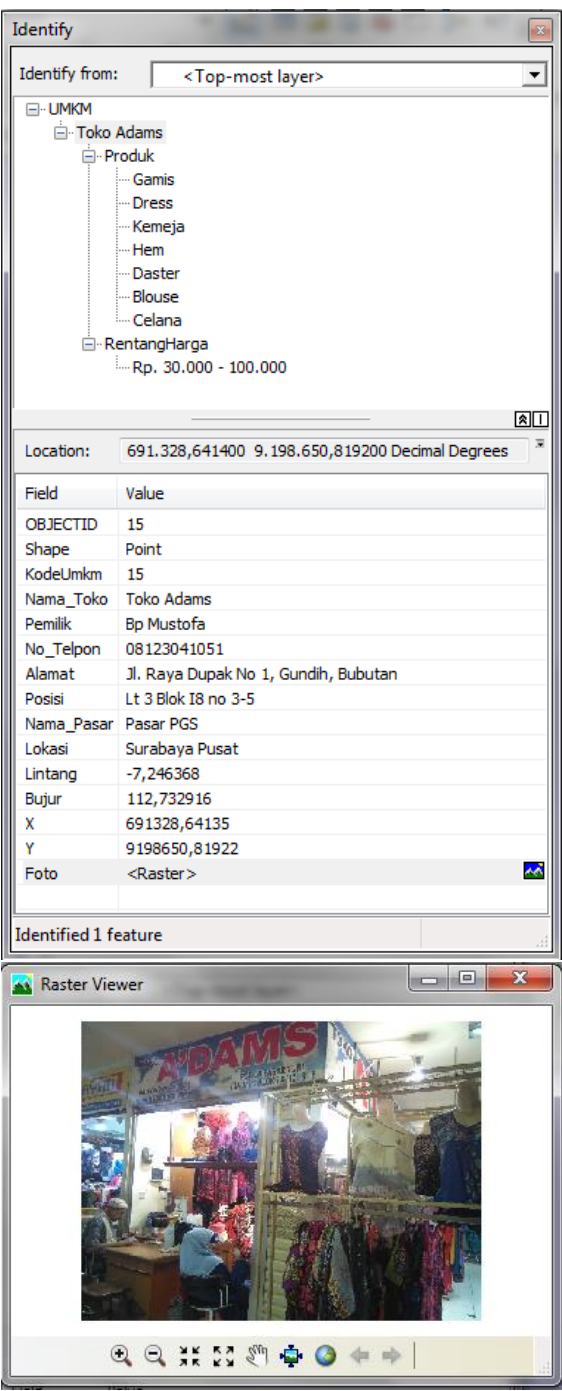

Gambar 5. Tampilan Hasil identify

Dalam aplikasi yang terbentuk, terdapat fungsi search yang dalam hal ini berfungsi sebagai identify antar atribut dan data spasial. Fungsi search ini terhubung langsung dengan database.

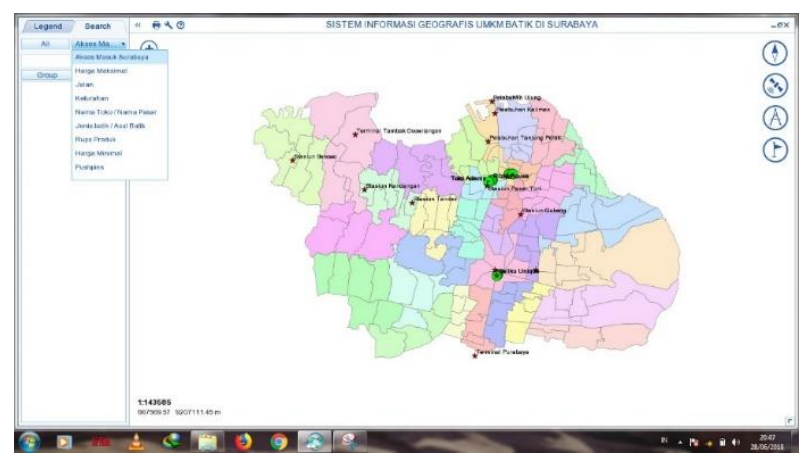

Gambar 6. Tampilan fungsi searh atribut

\section{Analisa Data}

Berdasarkan database serta persebaran 41 UMKM batik Surabaya yang terbentuk dapat disimpulkan 
bahwa UMKM batik Surabaya prioritas 1 atau prioritas tinggi banyak terdapat di Surabaya Selatan yaitu pasar DTC, prioritas 2 atau prioritas sedang banyak terdapat di Surabaya Pusat yaitu pasar Turi, pasar PGS dan pasar Atum, sedangkan prioritas 3 atau prioritas rendah banyak terdapat di Surabaya Utara yaitu Pasar ITC.

Tabel 12. Perhitungan Prioritas UMKM Batik Berdasarkan Pasar di Surabaya

\begin{tabular}{|c|c|c|c|c|c|c|}
\hline No & Pasar & $\begin{array}{c}\text { Jumlah } \\
\text { UMKM } \\
\text { Prioritas } \\
\text { Tinggi }\end{array}$ & $\begin{array}{l}\text { Jumlah } \\
\text { UMKM } \\
\text { Prioritas } \\
\text { Sedang }\end{array}$ & $\begin{array}{l}\text { Jumlah } \\
\text { UMKM } \\
\text { Prioritas } \\
\text { Rendah }\end{array}$ & Total & Keterangan \\
\hline 1 & DTC & 5 & 5 & 0 & 10 & $\begin{array}{c}\text { Prioritas } \\
\text { Tinggi }\end{array}$ \\
\hline 2 & Turi & 3 & 10 & 1 & 14 & $\begin{array}{l}\text { Prioritas } \\
\text { Sedang }\end{array}$ \\
\hline 3 & PGS & 3 & 7 & 0 & 10 & $\begin{array}{l}\text { Prioritas } \\
\text { Sedang }\end{array}$ \\
\hline 4 & Atum & 1 & 1 & 0 & 2 & $\begin{array}{c}\text { Prioritas } \\
\text { Sedang }\end{array}$ \\
\hline 5 & ITC & 1 & 1 & 3 & 5 & $\begin{array}{l}\text { Prioritas } \\
\text { Rendah }\end{array}$ \\
\hline
\end{tabular}

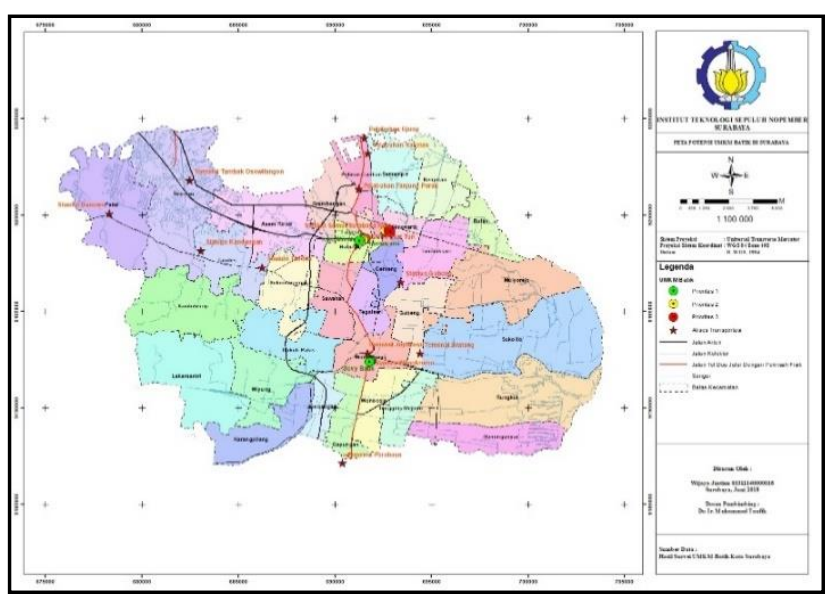

Gambar 7. Peta Potensi UMKM Batik Kota Surabaya

\section{KESIMPULAN}

Kesimpulan yang dapat diambil dari penelitian ini adalah sebagai berikut:

1. Potensi UMKM batik di Surabaya terbagi kedalam tiga prioritas, antara lain:

- Prioritas Tinggi atau I, adalah UMKM batik yang mempunyai skor $8-8,9$ sejumlah 13 UMKM dengan presentasi sebesar $32 \%$.

- Prioritas Sedang atau II, adalah UMKM batik yang mempunyai skor $7-7,9$ sejumlah 24 UMKM dengan presentasi sebesar $58 \%$.

- Prioritas Rendah atau III, adalah UMKM batik yang mempunyai skor $5-6,9$ sejumlah 4 UMKM dengan presentasi sebesar $10 \%$.
2. Persebaran UMKM batik di Surabaya antara lain:

- Prioritas Tinggi atau I antara lain 5 UMKM di Surabaya Selatan yaitu di pasar DTC, 6 UMKM di Surabaya Pusat yaitu 3 di pasar Turi dan 3 di pasar PGS, 1 UMKM di Surabaya Utara yaitu di pasar Atom, dan 1 UMKM di Surabaya Timur yaitu di pasar ITC.

- Prioritas Sedang atau II antara lain 5 UMKM di Surabaya Selatan yaitu di pasar DTC, 17 UMKM di Surabaya Pusat yaitu 10 di pasar Turi dan 7 di pasar PGS, 1 UMKM di Surabaya Utara yaitu di pasar Atom, dan 1 UMKM di Surabaya Timur yaitu di pasar ITC.

- Prioritas Rendah atau III antara lain 1 UMKM di Surabaya Pusat yaitu di pasar Turi dan 3 UMKM di Surabaya Timur yaitu di pasar ITC.

3. Dari hasil pengumpulan data dari hasil kuisioner UMKM batik di Surabaya maka diperoleh hasil berupa Sistem Informasi Geografis UMKM Batik Kota Surabaya

Adapun hal yang perlu dilakukan untuk penelitian selanjutnya adalah pada aplikasi Sistem Informasi Geografis Industri UMKM Batik di Surabaya diharapkan dapat dikembangkan oleh Dinas Koperasi dan UMKM Kota Surabaya yang kemudian dapat diaplikasikan untuk keperluan dinas sehingga dapat diperluas lagi untuk kasus Usaha Mikro, Usaha Kecil, dan Usaha Menengah, maupun jenis perdagangan dan perindustrian lainnya.

\section{DAFTAR PUSTAKA}

Anggraeni, Agmalia Dwi. (2016). Pembangunan Sistem Informasi Geografis Berbasis Web Untuk Pemetaan Persebaran Industri Kreatif Berbasis Budaya di Kota Surakarta. Surabaya: Institut Teknologi Sepuluh Nopember.

Ayuningsasi, A.A Ketut dan A.A Mirah Pradnya Paramita. (2013). Efektivitas dan Dampak Program Revitalisasi Pasar Tradisional di Pasar Agung Peninjoan. Bali: Universitas Udayana.

Aronof, S. (1991). Geographic Information Systems : A Management Perspective. Canada: WDL Publications Ottawa.

BatikInovatif. (2014). "Produk Kreatif Batik". http://binovatif.blogspot.co.id/2014/09/produkkreatif-batik.html. (Diakses pada tanggal 5 September 2017)

Beddington, Nadine. (1982). Design for Shopping Center. London: Butterworth Scientific Febriyanti. 
2010. Aplikasi Sistem Informasi Geografis Usaha Kecil dan Menengah Kota Depok Berbasis Web Menggunakan Quantum GIS. Universitas Gunadarma

Dahlia, Nadya Rizky. (2015). Evaluasi Usaha Kecil dan Menengah Menggunakan Sistem Informasi Geografis di Kota Surabaya. Surabaya: Institut Teknologi Sepuluh Nopember.Prahasta, E. (2001). Konsep - konsep Dasar Sistem Informasi Geografis. Bandung: Penerbit Informatika.

Fund, International Monetary. (2017). "Real GDP Growth". http://imf.org/external/datamapper.html. (Diakses pada tanggal 7 September 2017)

Kusumawardhani, R. (2012). How To Wear: Bagaimana Mengenal Batik, Memilih, Merawat, dan Menyesuaikannya dengan Tubuh dan Warna Kulit. Jakarta: PT. Gramedia Pustaka.

Lisbijanto, H. (2013). Batik. Yogyakarta: Graha IImu

Malczewski, J. (1999). GIS and Multicriteria Decision Analysis. New York: John Willey and Sons.

Musman, Asti \& Ambar B. Arini. (2011). Batik Warisan Adiluhung Nusantara. Yogyakarta: G-Media.

Raharjo, Beni dan Muhamad Ikhsan. (2015). Belajar ArcGIS Desktop 10: ArcGIS 10.2/10.3. Banjarbaru: Geosiana Press.

Scribd.com. (2017). "Macam - Macam Batik Indonesia berdasarkan asal daerahnya". https://www.scribd.com/doc/252587395/Macam -Macam-Motif-Batik-Indonesia-Beserta-DaerahAsalnya. (Diakses pada tanggal 5 September 2017)

Statistik, Badan Pusat. (2017). "Perkembangan UMKM Periode 2016 - 2017". https://bps.go.id/staticable/tabel-perkembanganumkm-pada-periode-2016--2017.html. (Diakses pada tanggal 7 September 2017)

Trenggana, Hendry Meilano. (2012). Analisis Potensi Dan Hambatan Yang Dihadapi Umkm Dalam Mengembangkan Usaha Dengan Menggunakan Alat Bantu Sistem Informasi Geografis (Sig): Studi Kasus Kecamatan Pancoran Mas, Kota Depok. Depok: Universitas Gunadarma.

Undang-Undang Republik Indonesia. "Nomor 20 Tahun 2008 Tentang Usaha Mikro, Kecil, dan Menengah". http://www.bi.go.id/id/tentang-bi/uubi/Documents/UU20Tahun2008UMKM.pdf. (Diakses pada tanggal 4 September 2017)

Wijaya, Daniel Agung. (2015). Studi Perencanaa Lokasi Tempat Pembuangan Akhir (TPA) Menggunakan Sistem Informasi Geografis Dengan Metode Simple Additive Weighting (SAW) (Studi Kasus: Kota Surabaya). Surabaya: Institut Teknologi Sepuluh Nopember. 